BMJ Open

Sport \&

Exercise

Medicine

\title{
Ankle to brachial systolic pressure index at rest increases with age in asymptomatic physically active participants
}

\author{
Florian Congnard, ${ }^{1}$ Pierre Abraham, ${ }^{2}$ François Vincent, ${ }^{3}$ Thierry Le tourneau, ${ }^{4}$ \\ François Carre, ${ }^{5}$ David Hupin, ${ }^{6}$ Jean François Hamel, ${ }^{2}$ Bruno Vielle, ${ }^{2}$ \\ Antoine Bruneau ${ }^{2}$
}

To cite: Congnard $F$, Abraham P, Vincent $F$, et al. Ankle to brachial systolic pressure index at rest increases with age in asymptomatic physically active participants. BMJ Open Sport Exerc Med 2015;1: e000081. doi:10.1136/ bmjsem-2015-000081

- Prepublication history for this paper is available online. To view these files please visit the journal online (http://dx.doi.org/10.1136/ bmjsem-2015-000081).

Accepted 28 October 2015 CrossMark

\footnotetext{
${ }^{1}$ Physical Activity and Sport Learning Institute (IFEPSA), Les Ponts-de-Cé, France

${ }^{2}$ University Hospital, Angers, France

${ }^{3}$ University Hospital, Limoges, France

${ }^{4}$ Inserm U1087, Institute of Thorax, University Hospital, Nantes, France

${ }^{5}$ University Hospital, Rennes, France

${ }^{6}$ Department of Clinical and Exercise Physiology, EA SNA EPIS 4607, University Hospital of Saint-Etienne, University of Lyon, SaintEtienne, France
}

Correspondence to Dr Pierre Abraham; Piabraham@chu-angers.fr

\section{ABSTRACT}

Background: It is commonly acknowledged that the ability to use the ankle-brachial index (ABI), a reliable way to diagnose atherosclerosis, decreases with age in the general population. The aim of this study was to determine the relationship between resting $A B I$ and age in different populations.

Methods: 674 physically active participants with (active high risk, ACT $\mathrm{HR}_{\mathrm{R}}$ ) or without (active low risk, $A C T_{L R}$ ) cardiovascular risk factors or/and sedentary (SED) subjects, aged 20-70 years. Systolic arterial pressure was recorded at rest and simultaneously with automatic sphygmomanometers at the arms and ankles. ABI was calculated as the ratio of the lowest, highest or mean ankle pressure to the highest arm pressure.

Results: Proportion of $A B I_{\min }<0.90$ was $10.3 \%$ in SED HR $_{\text {HR }}$ subjects versus $0.5 \%$ and $1.2 \%$, respectively, in $A C T_{H R}$ and $A C T_{L R}$ groups. The averaged $A B I$ value of each group was in the normal range in all groups $(A B \mid>0.90)$ but was significantly lower in $S D_{H R}$ compared with all active participants $(p<0.001)$. Regression lines from $A B I_{\text {mean }}$ versus age could lead to approximately +0.05 every 15 years of age in apparently healthy active participants (ACT $T_{L R}$ ).

Conclusion: $A B I$ at rest increases with the increase in age in the groups of low-risk asymptomatic middle-aged trained adults. The previously reported decrease in $\mathrm{ABI}$ with age is found only in $S E D_{H R}$ subjects, and is very likely to rely on the increased prevalence of asymptomatic arterial disease in this group. The increase of $A B I$ with age is consistent with the 'physiological' stiffness observed in ageing arteries even in the absence of 'pathological' atherosclerotic lesions.

Trial registration number: NIH clinicaltrial.gov: NCT01812343.

\section{INTRODUCTION}

Atherosclerosis is a widely prevalent disease, especially in Western countries. Numerous risk factors are known to increase the risk of atherosclerosis, including age, diabetes,

\section{Key messages}

- This is the first study to report that resting ankle-brachial index (ABI) increases with age in asymptomatic and physically active participants without risk factors.

- The decrease of $A B I$ value with age could be due to the increase in the prevalence of asymptomatic peripheral artery disease in older participants.

- This study suggests that the so-called borderline or low normal $A B I$ (in the range 0.90-0.99) remains to be studied by considering the age of the participant.

hypertension, dyslipidaemia, smoking status and history of familial cardiovascular events. ${ }^{12}$ Ankle to brachial systolic arterial pressure index (ABI) has largely been validated as an accurate way of detecting peripheral artery disease (PAD), even in asymptomatic patients. ${ }^{3}$ It is generally acknowledged that ABI decreases with age in the general population, ${ }^{4}$ although conflicting results can be found. ${ }^{5}$ This inverse ABI-to-age relationship observed in population studies is likely to result from an increased prevalence of asymptomatic lower limb arterial stenosis in the elderly ('pathological' ageing). On the contrary, remodelling of the arterial wall with age ('physiological' ageing) results in arterial stiffness, ${ }^{67}$ and arterial stiffness is known to increase ABI or even lead to noncompressible ankle arteries. ${ }^{8}$ Therefore, in participants without stenosis, ABI should increase with age.

One way of excluding most potential cases of stenosis and getting an idea of the ABI-to-age relationship resulting from the 'physiological' ageing of the arterial wall, is by focusing on physically active and 
asymptomatic participants. Indeed, during exercise, even very mild to moderate stenosis becomes symptomatic whereas these lesions remain asymptomatic in sedentary subjects. ${ }^{9}$ Hence, physically active and asymptomatic participants are very unlikely to present even mild stenosis. We hypothesised that: (1) on the one hand, in such physically active and asymptomatic participants without cardiovascular risk factors, instead of the usually reported negative relationship between resting $\mathrm{ABI}$ and age, we would find a positive relationship as a result of arterial wall remodelling with age, (2) on the other hand, using the same technique, the usual inverse relationship between $\mathrm{ABI}$ and age would be found in asymptomatic but sedentary subjects with cardiovascular risk factor, as a result of significant stenosis that remains asymptomatic due to low-activity level.

\section{METHODS}

This multicentre retrospective study was performed among patients with no history of cardiovascular disease and reporting no lower limb symptoms. All participants were referred to departments of sports medicine for the systematic evaluation of exercise performance or departments of vascular investigations to evaluate the presence or absence of PAD from ABI screening in patients with cardiovascular risk factors. In all participants, medical examination reports were used to bring out the presence or absence of cardiovascular risk factors (smoking status, hypertension, diabetes mellitus, dyslipidaemia, familial history of cardiovascular events). Although the gender of a participant could be considered a risk factor, each group consisted of males as well as females. Characteristics of the participants were recorded from a standard questionnaire, interview and physical evaluation. Only patients not reporting the use of cardiovascular drugs, lipid-lowering agent, any kind of limb pain at rest or exercise, or a history of cardiovascular disease, were included in the present study.

\section{Procedure}

Anthropometric data were recorded and ABI measured with automatic devices. Indeed, in the past few years, multiple devices have become available to automatically measure arm and ankle systolic pressures and determine $\mathrm{ABI}$, in order to facilitate routine screening for PAD. ${ }^{10}$ These automatic devices are rapidly spreading ${ }^{11-17}$ and have been extensively used in previous studies. ${ }^{9} 18 \quad 19$ One of the major interests of automatic determination is to homogenise the measurement between various operators. Ankle and arm pressures were measured automatically using four Dynamap Critikon V100 $15 \mathrm{~cm}$ large cuff sphygmomanometers (Johnson and Johnson, France), with the participant resting supine for at least $5 \mathrm{~min}$. ABI was calculated for each leg using the highest arm pressure as a denominator. The numerator was either: the maximal $\left(\mathrm{ABI}_{\max }\right)$, minimal $\left(\mathrm{ABI}_{\min }\right)$ or mean $\left(\mathrm{ABI}_{\text {mean }}\right)$ of the two ankle pressures.

\section{Subjects}

From our database, we retrieved 674 participants fulfilling the inclusion criteria. Patients were divided into three groups. The first group (sedentary high risk, SED $\left._{\mathrm{HR}}\right)$, comprised of sedentary subjects referred to the vascular unit for systematic vascular investigations due to their risk factors. All these patients had one or multiple cardiovascular risk factors and reported no significant leisure physical activity. The other two groups consisted of asymptomatic physically active participants referred to sports medicine departments for the evaluation of their leisure physical activity. Among these asymptomatic and active participants, the second group included participants with one or more cardiovascular risk factors (active high risk, $\mathrm{ACT}_{\mathrm{HR}}$ ) and the third group included those reporting no cardiovascular risk factors (active low risk, $\left.\mathrm{ACT}_{\mathrm{LR}}\right)$. The study protocol conforms to the ethical guidelines of the 1975 Declaration of Helsinki as reflected in a priori approval by the institution's human research committee. The study was registered in the NIH clinicaltrial.gov database under reference NCT01812343.

\section{Statistical analysis}

Analyses were performed using SPSS software, V.17. Quantitative variables are presented as mean $\pm \mathrm{SD}$. Analysis of variance was used to compare continuous variables in the three groups. Linear regression was employed to describe the ABI-to-age relationship and its underlying hypotheses were verified. General linear model was used to compare the slopes of regression lines.

\section{RESULTS}

In brief, 674 participants aged $51.7 \pm 10.4$ years; weight $76.7 \pm 14.6 \mathrm{~kg}$; stature $1.72 \pm 0.08 \mathrm{~m}$; body mass index (BMI) 26.0 \pm 4.8 , were included in this study. Anthropometric characteristics and cardiovascular risk factors for each group are shown in tables 1 and 2 .

$\mathrm{SED}_{\mathrm{HR}}$ subjects logically had a mean weight and BMI significantly higher than active participants, either $\mathrm{ACT}_{\mathrm{HR}}$ or $\mathrm{ACT}_{\mathrm{LR}}(\mathrm{p}<0.001)$. There were significant differences between the mean ages of the three groups $(\mathrm{p}<0.001)$.

Regarding cardiovascular risk factors (table 2), of interest to note is that in the $\mathrm{ACT}_{\mathrm{HR}}$ subjects, the proportion of participants having one or two cardiovascular risk factors, was higher than for $\mathrm{SED}_{\mathrm{HR}}$. However, $\mathrm{SED}_{\mathrm{HR}}$ subjects were more likely to accumulate at least three cardiovascular risk factors. The major risk factor observed in $\mathrm{ACT}_{\mathrm{HR}}$ subjects was smoking status and a history of familial cardiovascular events. In contrast, in $\mathrm{SED}_{\mathrm{HR}}$ subjects, a large proportion of participants with diabetes was found.

Few participants had an $\mathrm{ABI}<0.90$. Taking the $\mathrm{ABI}_{\text {min }}$ as a reference, proportion of $\mathrm{ABI}_{\min }<0.90$ was $10.3 \%$, $0.5 \%$ and $1.2 \%$, in $\mathrm{SED}_{\mathrm{HR}}, \mathrm{ACT}_{\mathrm{HR}}$ and $\mathrm{ACT}_{\mathrm{LR}}$ subjects, 
Table 1 Characteristics of included participants at rest

\begin{tabular}{|c|c|c|c|c|}
\hline & $\begin{array}{l}\text { Active low risk } \\
\left(\mathrm{ACT}_{\mathrm{LR}}\right)\end{array}$ & $\begin{array}{l}\text { Active high risk } \\
\left(\mathrm{ACT}_{\mathrm{HR}}\right)\end{array}$ & $\begin{array}{l}\text { Sedentary high risk } \\
\left(\text { SED }_{\mathrm{HR}}\right)\end{array}$ & $\begin{array}{l}\text { p } \\
\text { Value }\end{array}$ \\
\hline $\mathrm{n}$ & 252 & 218 & 204 & - \\
\hline Males/females & $223 / 29^{\star}$ & $175 / 43$ & $149 / 55$ & $<0.001$ \\
\hline Age (years) & $48.5 \pm 10.5^{*} \dagger$ & $50.4 \pm 9.5^{*}$ & $56.9 \pm 9.1$ & $<0.001$ \\
\hline Weight (kg) & $74.1 \pm 11.4^{*}$ & $75.9 \pm 14.0^{*}$ & $80.9 \pm 17.8$ & $<0.001$ \\
\hline Height (m) & $1.74 \pm 0.07$ & $1.73 \pm 0.09$ & $1.68 \pm 0.08$ & 0.151 \\
\hline Body mass index $\left(\mathrm{kg} / \mathrm{m}^{2}\right)$ & $24.4 \pm 3.2^{*}$ & $25.2 \pm 3.8^{*}$ & $28.7 \pm 6.1$ & $<0.001$ \\
\hline Power output (W) & $249 \pm 55$ & $221 \pm 59$ & Not available & - \\
\hline $\begin{array}{l}\text { Minimal ankle-brachial index } \\
\left(A B I_{\min }\right)\end{array}$ & $1.15 \pm 0.10^{\star}$ & $1.14 \pm 0.10^{*}$ & $1.08 \pm 0.14$ & $<0.001$ \\
\hline $\begin{array}{l}\text { Maximal ankle-brachial index } \\
\left(A B I_{\max }\right)\end{array}$ & $1.20 \pm 0.10^{*}$ & $1.20 \pm 0.09^{*}$ & $1.16 \pm 0.14$ & $<0.001$ \\
\hline $\begin{array}{l}\text { Mean ankle-brachial index } \\
\left(\mathrm{ABI} \mathrm{I}_{\text {mean }}\right)\end{array}$ & $1.17 \pm 0.09^{\star}$ & $1.17 \pm 0.09^{\star}$ & $1.12 \pm 0.13$ & $<0.001$ \\
\hline
\end{tabular}

respectively. Comparable results were observed using $\mathrm{ABI}_{\text {mean }}$ as reference-the proportion of $\mathrm{ABI}_{\text {mean }}<0.90$ was $4.4 \%, 0.0 \%$ and $0.8 \%$, in $\mathrm{SED}_{\mathrm{HR}}, \mathrm{ACT}_{\mathrm{HR}}$ and $\mathrm{ACT}_{\mathrm{LR}}$ subjects, respectively. Lastly, only six $\mathrm{SED}_{\mathrm{HR}}$ subjects (2.4\%) had an $\mathrm{ABI}_{\max }<0.90$. On average, as shown in table 1, the ABI observed in $\mathrm{SED}_{\mathrm{HR}}$ subjects was lower than that in the other two groups, regardless of the method of calculation. In asymptomatic active participants, no significant differences were observed between the average ABI of high-risk or low-risk participants, regardless of the calculation mode $(\mathrm{p}=0.456,0.931$ and 0.663 , respectively, for $\mathrm{ABI}_{\text {min }}, \mathrm{ABI}_{\text {max }}$ and $\mathrm{ABI}_{\text {mean }}$ ).

Finally, regression lines were $\mathrm{ABI}_{\text {mean }}=-0.02$ age $/ 10$ +1.23 for $\mathrm{SED}_{\mathrm{HR}}, \mathrm{ABI}_{\text {mean }}=+0.01$ age $/ 10+1.14$ for $\mathrm{ACT}_{\mathrm{HR}}$ and $\mathrm{ABI}_{\text {mean }}=+0.03$ age $/ 10+1.04$ for $\mathrm{ACH}_{\mathrm{LR}}$ (figure 1). Slopes were significantly different between groups: $p=0.01$ for $A_{C T} T_{L R}$ versus $A_{C T}, p<0.001$ for $A_{H C T}$ versus $\mathrm{SED}_{\mathrm{HR}}$ and $\mathrm{p}=0.04$ for $\mathrm{ACT}_{\mathrm{HR}}$ versus $\mathrm{SED}_{\mathrm{HR}}$.
Comparable results were observed for relationships of $\mathrm{ABI}_{\text {min }}$ versus age and $\mathrm{ABI}_{\text {max }}$ versus age, as shown in figure 1 .

\section{DISCUSSION}

To the best of our knowledge, this is the first study reporting resting $\mathrm{ABI}$ in asymptomatic and physically active participants without risk factors (ie, very unlikely to suffer even mild stenosis), in asymptomatic and physically active participants with risk factors, and in asymptomatic sedentary subjects with risk factors (ie, where mild to moderate PAD is likely to remain asymptomatic due to inactivity). Note that the average ABI value of this population was generally in the normal range $\left(1.30>\mathrm{ABI}_{\text {rest }}>0.90\right)$. The finding that $\mathrm{ABI}$ at rest does not decrease (but increases) with age in $\mathrm{ACT}_{\mathrm{LR}}$ is consistent with our initial hypothesis, and appears logical

Table 2 Occurrence frequencies of various risk factors of overall participants

\begin{tabular}{|c|c|c|c|}
\hline & $\begin{array}{l}\text { Active low risk } \\
\left(\mathrm{ACT}_{\mathrm{LR}}\right)\end{array}$ & $\begin{array}{l}\text { Active high risk } \\
\left(\mathrm{ACT}_{\mathrm{HR}}\right)\end{array}$ & $\begin{array}{l}\text { Sedentary high risk } \\
\left(\text { SED }_{\mathrm{HR}}\right)\end{array}$ \\
\hline \multicolumn{4}{|l|}{ Number of risk factors (\%) } \\
\hline 0 & 100 & 0 & 0 \\
\hline 1 & 0 & 78.9 & 69.6 \\
\hline 2 & 0 & 18.8 & 16.2 \\
\hline 3 & 0 & 2.3 & 12.2 \\
\hline 4 & 0 & 0 & 2.0 \\
\hline Smoking status, & $0 / 252$ & $183 / 35$ & $24 / 180$ \\
\hline Smoker (active+former)/no smoker, n (\%) & $(0) / 100$ & $(83.9) /(16.1)$ & $(11.8) /(88.2)$ \\
\hline Hypertension, n (\%) & $0(0)$ & $19(8.7)$ & $62(30.4)$ \\
\hline Diabetes mellitus, n (\%) & $0(0)$ & $2(0.9)$ & $157(77.0)$ \\
\hline Dyslipidaemia, n (\%) & $0(0)$ & $41(18.8 \%)$ & $47(23.0)$ \\
\hline $\begin{array}{l}\text { Familial history of cardiovascular (CV) events, } \\
n(\%)\end{array}$ & $0(0)$ & $66(30.3)$ & $9(4.4)$ \\
\hline Average of $\mathrm{CV}$ risk factors, $\mathrm{n}$ & 0 & 1.2 & 1.5 \\
\hline
\end{tabular}



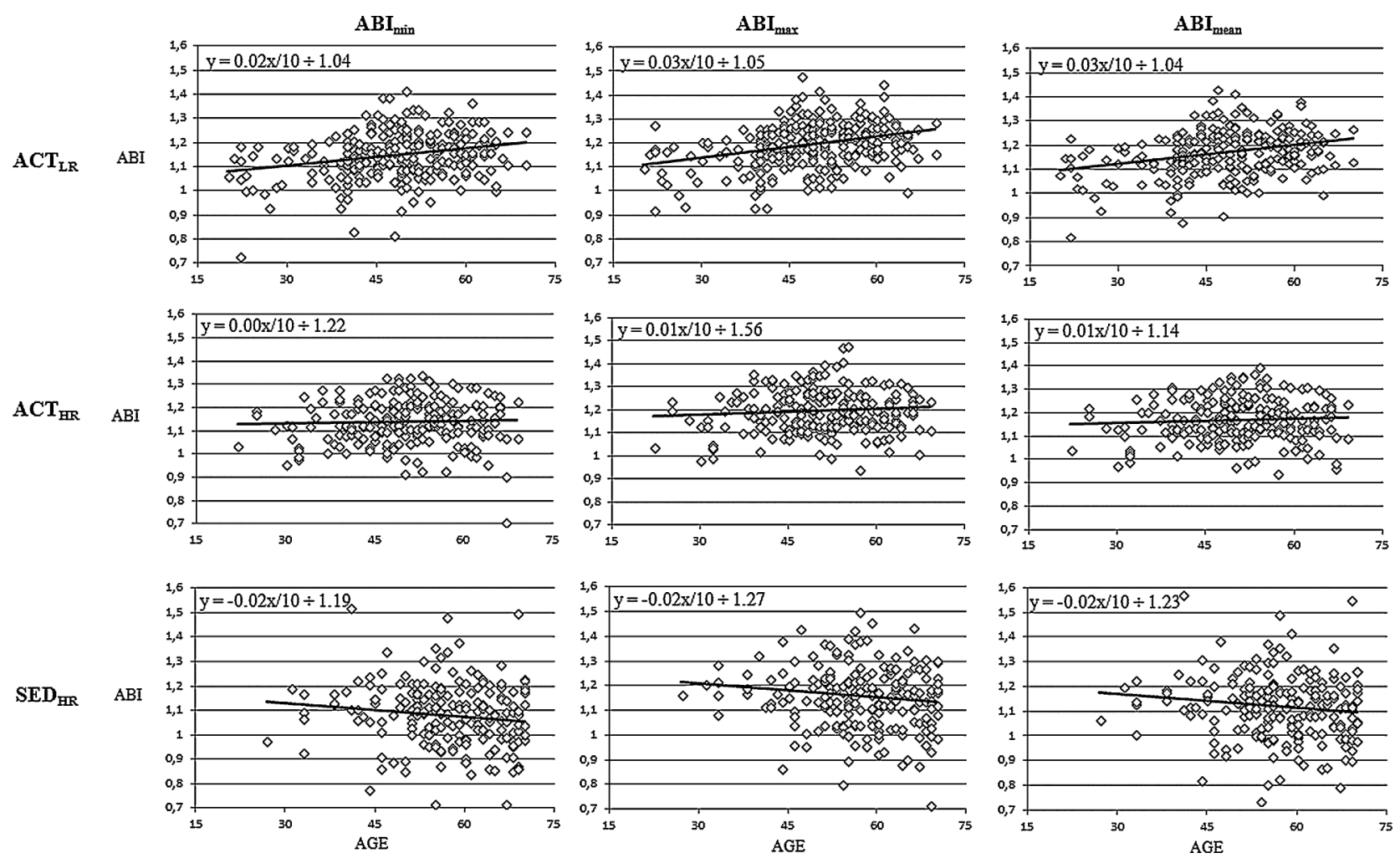

Figure $1 A B I_{\text {min }}, A B I_{\text {max }}$ or $A B I_{\text {mean }}$-to-age scatterplots and regression lines for $A C T_{H R}, A C T_{L R}$ and $S E D_{H R}(A B I$, ankle-brachial index; $A C T_{H R}$, active high risk; $A C T_{L R}$, active low risk; $S E D_{H R}$, sedentary high risk).

with the expected 'physiological' ageing of the arterial wall. On the contrary, we found the expected decrease of $\mathrm{ABI}$ with age in the $\mathrm{SED}_{\mathrm{HR}}$ population. Interestingly, the slope of the relationship of $\mathrm{ABI}$ to age in the $\mathrm{ACT}_{\mathrm{HR}}$ subjects is half way between the two other regression analyses. We contend that these observations objectively support the assumption that the decrease of ABI value with age is due to the increase in the prevalence of asymptomatic PAD in older participants, whereas ABI 'physiologically' increases with age.

It is commonly accepted that $\mathrm{ABI}<0.90$ at rest is the most common and agreed on value, having reported acceptable levels of sensitivity and specificity ${ }^{4} 20$ to detect PAD. Nevertheless, this cut-off was determined on populations with proven PAD or in advanced age populations. ${ }^{21}$ The results of our study present a "physiological' trend of resting ABI to increase by approximately +0.05 every 15 years of age in apparently healthy subjects. Thus, the use of a cut-off point of $\mathrm{ABI}<0.90$, could overestimate the prevalence of PAD in the young, while this could underestimate the prevalence of PAD in the elderly. This could also be an explanation for the fact that the sensitivity of $\mathrm{ABI}$ is reportedly decreased in elderly patients. ${ }^{22}$

There are limitations to the present study. First, it may be that our observation results from a technical issue. Whether automatic devices are equally accurate in young or old participants has never been studied. The fact that automatically determined pressures overestimate the pressure that would be observed in manual recordings, especially for low-pressure values, cannot consistently be excluded. ${ }^{10} 23$ This potential overestimation should explain the difference between groups. Second, it could be argued that physically active patients are more likely to have higher ABI values than participants with low physical activity levels. ${ }^{24}$ This is also true, and we found a similar trend in our group in terms of average ABI value within each group. Nevertheless, the ABI to age relationship was analysed in groups with a relatively homogeneous activity level (Power Output $\mathrm{ACT}_{\mathrm{LR}}$ vs $\left.\mathrm{ACT}_{\mathrm{HR}}: \mathrm{p}=0.433\right)$. Third, we provide no argument that the increased trend of ABI with ageing in $\mathrm{ACT}_{\mathrm{LR}}$ is related to arterial stiffening. Previous studies have reported a weak but significant association between a high ABI and high pulse wave velocity. ${ }^{25}$ Further investigations are needed in $\mathrm{ACT}_{\mathrm{LR}}$ subjects to correlate $\mathrm{ABI}$ measurements to measurements of arterial stiffness. Fourth, no ultrasound imaging was carried out to exclude those patients who might have had mild to moderate arterial ultrasound lesions. We advocate that this would have been of little interest because, in sportsrelated claudication, even extremely localised and mild lesions may become symptomatic, as illustrated by endofibrosis in athletes. ${ }^{26}{ }^{27}$ The sensitivity of ultrasound to detect these extremely moderate lesions would be relatively low. Inversely, we think that it is unlikely that the absence of decrease of ABI resulted from undetected severe stenoses, since ABI decreases with the severity of endoluminal lesions. Lastly, on the one hand, our groups show a very high proportion of males and 
Caucasian participants. Thereby, our results would require confirmation due to the differences in $\mathrm{ABI}$ that are reported between males and females or between black and Caucasian participants. ${ }^{28}$ On the other hand, extrapolation to other automatic devices is needed as well as confirmation with manual recordings. It should be kept in mind that the variability of manual recording is high and depends on the observer experience. Using automatic devices allowed us to get rid of interindividual variability ${ }^{29}$ and to reduce the time of measurement. ${ }^{30}$

In conclusion, the present study provides, for the first time, objective evidence that the 'physiological' change in ABI increases with age. This reinforces the belief that the decrease in ABI at rest with age observed in general population studies likely results from the increased prevalence of participants with subclinical PAD. This may also question whether the same resting $A B I$ value should be used as a cut-off point in the youngest and oldest participants. Specifically, the present study suggests that the so-called borderline or low normal ABI (in the range of $0.90-0.99$ ) is more likely to predict the presence of PAD in older than in younger patients.

Acknowledgements The authors would like to thank the CRC d'Angers, I Laporte and M Gernigon, for technical help.

Funding The study was promoted by the University Hospital in Angers and supported by grants from PHRC-IR 2012, SORMES, CD0S49, DDJS49, Mairie d'Angers. FC benefits from the support of APCOSS (IFEPSA).

Competing interests None declared.

Ethic approval This study and templates informed consent forms had been reviewed and approved by the Ethics Committee CPP-OUEST II (France).

Provenance and peer review Not commissioned; internally peer reviewed.

Data sharing statement No additional data are available.

Open Access This is an Open Access article distributed in accordance with the Creative Commons Attribution Non Commercial (CC BY-NC 4.0) license, which permits others to distribute, remix, adapt, build upon this work noncommercially, and license their derivative works on different terms, provided the original work is properly cited and the use is non-commercial. See: http:// creativecommons.org/licenses/by-nc/4.0/

\section{REFERENCES}

1. Selvin E, Erlinger TP. Prevalence of and risk factors for peripheral arterial disease in the United States: results from the National Health and Nutrition Examination Survey, 1999-2000. Circulation 2004;110:738-43.

2. McDermott MM, Liu K, Criqui MH, et al. Ankle-brachial index and subclinical cardiac and carotid disease: the multi-ethnic study of atherosclerosis. Am J Epidemiol 2005;162:33-41.

3. Norgren L, Hiatt WR, Dormandy JA, et al. Inter-Society Consensus for the Management of Peripheral Arterial Disease (TASC II). Eur J Vasc Endovasc Surg 2007;33(Suppl 1):S1-75.

4. Aboyans V, Criqui $\mathrm{MH}$, Abraham $\mathrm{P}$, et al. Measurement and interpretation of the ankle-brachial index: a scientific statement from the American Heart Association. Circulation 2012;126:2890-909.

5. Ishida A, Miyagi M, Kinjo K, et al. Age- and sex-related effects on ankle-brachial index in a screened cohort of Japanese: the Okinawa Peripheral Arterial Disease Study (OPADS). Eur J Prev Cardiol 2014;21:712-18.

6. Reneman RS, van Merode T, Hick P, et al. Age-related changes in carotid artery wall properties in men. Ultrasound Med Biol 1986;12:465-71.

7. Vermeersch SJ, Rietzschel ER, De Buyzere ML, et al. Age and gender related patterns in carotid-femoral PWV and carotid and femoral stiffness in a large healthy, middle-aged population. J Hypertens 2008;26:1411-19.
8. Resnick HE, Lindsay RS, McDermott MM, et al. Relationship of high and low ankle brachial index to all-cause and cardiovascular disease mortality: the Strong Heart Study. Circulation 2004;109:733-9.

9. Abraham P, Bickert S, Vielle B, et al. Pressure measurements at rest and after heavy exercise to detect moderate arterial lesions in athletes. J Vasc Surg 2001;33:721-7.

10. Beckman JA, Higgins CO, Gerhard-Herman M. Automated oscillometric determination of the ankle-brachial index provides accuracy necessary for office practice. Hypertension 2006;47:35-8.

11. Benchimol A, Bernard V, Pillois X, et al. Validation of a new method of detecting peripheral artery disease by determination of ankle-brachial index using an automatic blood pressure device. Angiology 2004;55:127-34.

12. Aboyans V, Lacroix $P$, Doucet $S$, et al. Diagnosis of peripheral arterial disease in general practice: can the ankle-brachial index be measured either by pulse palpation or an automatic blood pressure device? Int J Clin Pract 2008;62:1001-7.

13. Arevalo-Manso JJ, Juarez-Martin B, Fernandez-Rodriguez G, et al [Diagnostic accuracy of an automatic blood pressure device for ankle brachial index determination in ischemic stroke patients]. Rev Neurol 2012;55:129-36.

14. Rosenbaum D, Rodriguez-Carranza S, Laroche $P$, et al. Accuracy of the ankle-brachial index using the SCVL(®), an arm and ankle automated device with synchronized cuffs, in a population with increased cardiovascular risk. Vasc Health Risk Manag 2012:8:239-46.

15. Wohlfahrt $\mathrm{P}$, Ingrischova $\mathrm{M}$, Krajcoviechova $\mathrm{A}$, et al. A novel oscillometric device for peripheral arterial disease screening in everyday practice. The Czech-post MONICA study. Int Angiol 2011;30:256-61.

16. Harrison ML, Lin HF, Blakely DW, et al. Preliminary assessment of an automatic screening device for peripheral arterial disease using ankle-brachial and toe-brachial indices. Blood Press Monit 2011:16:138-41.

17. Li B, Gao H, Li X, et al. Correlation between brachial-ankle pulse wave velocity and arterial compliance and cardiovascular risk factors in elderly patients with arteriosclerosis. Hypertens Res 2006;29:309-14.

18. Abraham P, Desvaux B, Saumet JL. Ankle-brachial index after maximum exercise in treadmill and cycle ergometers in athletes. Clin Physiol 1998;18:321-6.

19. Bruneau A, Le Faucheur A, Mahe G, et al. Endofibrosis in athletes: is a simple bedside exercise helpful or sufficient for the diagnosis? Clin J Sport Med 2009;19:282-6.

20. Al-Qaisi M, Nott DM, King DH, et al. Ankle brachial pressure index (ABPI): an update for practitioners. Vasc Health Risk Manag 2009:5:833-41.

21. Carter SA. Indirect systolic pressures and pulse waves in arterial occlusive diseases of the lower extremities. Circulation 1968;37:624-37.

22. Dachun $X$, Jue L, Liling $Z$, et al. Sensitivity and specificity of the ankle-brachial index to diagnose peripheral artery disease: a structured review. Vasc Med 2010;15:361-9.

23. Diehm N, Dick F, Czuprin C, et al. Oscillometric measurement of ankle-brachial index in patients with suspected peripheral disease: comparison with Doppler method. Swiss Med Wkly 2009;139:357-63.

24. Gardner AW, Sieminski DJ, Montgomery PS. Physical activity is related to ankle/brachial index in subjects without peripheral arterial occlusive disease. Angiology 1997;48:883-91.

25. Khandanpour N, Armon MP, Jennings B, et al. The association between ankle brachial pressure index and pulse wave velocity: clinical implication of pulse wave velocity. Angiology 2009;60:732-8.

26. Alimi YS, Accrocca $F$, Barthèlemy $P$, et al. Comparison between duplex scanning and angiographic findings in the evaluation of functional iliac obstruction in top endurance athletes. Eur J Vasc Endovasc Surg 2004;28:513-19.

27. Abraham P, Bouye P, Quere I, et al. Past, present and future of arterial endofibrosis in athletes: a point of view. Sports Med 2004;34:419-25.

28. Aboyans V, Criqui $\mathrm{MH}$, McClelland RL, et al. Intrinsic contribution of gender and ethnicity to normal ankle-brachial index values: the Multi-Ethnic Study of Atherosclerosis (MESA). J Vasc Surg 2007;45:319-27.

29. Richart T, Kuznetsova T, Wizner B, et al. Validation of automated oscillometric versus manual measurement of the ankle-brachia index. Hypertens Res 2009;32:884-8.

30. Congnard F, Bruneau A, Abraham P, et al. Time and reliability issues associated with automatic vs. manual measurements of Ankle to Brachial pressure Index (ABI) following heavy load exercise. J Sci Med Sport 2015;18:737-41. 